\title{
RANKING NON-DOMINATED SOLUTIONS IN AUTOMATED HIGHWAY DESIGN USING THE ANALYTIC NETWORK PROCESS (ANP)
}

\author{
Soknath Mil \\ School of Civil Engineering and Technology, \\ Sirindhorn International Institute of Technology, Thammasat University \\ P.O.Box 22, Pathum Thani 12121, Thailand. \\ soknath.siit@gmail.com, \\ Mongkut Piantanakulchai \\ School of Civil Engineering and Technology, \\ Sirindhorn International Institute of Technology, Thammasat University \\ P.O.Box 22, Pathum Thani 12121, Thailand. \\ mongkutp@gmail.com
}

\begin{abstract}
Construction of new highway projects needs a lot of consideration to be taken into account during the design process. The complexity of the process and its repetitive (trial and error) nature put forward the need for the development of computer aided/automated design. During the past decades, many researchers have been interested in this problem. The most advanced research in automated highway alignment design is multi-objective 3D alignment optimization which produces a set of nondominated solutions (Pareto Front Optimality). This paper presents the use of Analytic Network Process (ANP) methodology to prioritize alignments from a set of non-dominated solutions. ANP provides comprehensive framework for the assessment of highway alignment design. From the result of multi-objective optimization process, alignments are provided with their objective values. In this study, the construction cost, user cost, environmental impact and social impact are the main objectives with sub-objectives inside. Based on the valuations from experts and previous literature reviews, relative priorities between objectives are set. The priorities in feedback loops are determined based on dominant features of each alternative. A case study was conducted to investigate the efficiency of the model. The alignments from a set of non-dominated solutions using multi-objective optimization were selected using the clustering technique. Finally, the ANP was used to determine the priorities of alternatives (alignments). ANP could further assist the decision makers to prioritize non-dominated solutions according to their preferences.
\end{abstract}

Keywords: Highway Costs, Multi-Objective Optimization, Multi-Criterion Decision making (MCDM), Pareto Front Optimality, Non-Dominated Solution Set, Analytic Network Process (ANP)

\section{Introduction}

To meet the general needs of traffic growth, the improvement of existing road or construction of new roads are needed. It has a significant impact on regional economic and as well as long-term effects on the community. Thus, it is essential that the government has to make a reasonable decision. However, the decision is quite complicated since the problem is multi-disciplinary which requires the cooperation among different parties. The appropriate economic tool for these instances is benefit-cost analysis (BCA), which considers life-cycle benefits as well as life-cycle costs (FHWA, 2003). Even though, it is not the best choice for assessing qualitative contexts such as social or political view, since the dollar equivalence measures may not necessarily represent such opinion adequately (Shang et al.,

\footnotetext{
* Corresponding author
} 
2004). Moreover, CBA is a single-criterion decision making technique which may not be suitable to the problem of highway design dealing with the social, technical, political, economic, and environmental factors. The Multi-Criterion Decision Making (MCDM) is more preferable. The MCDM in highway planning can be found in literatures. For example, Kalamaras et al. (2000) proposed multi-criteria analysis to select the best highway alignment. Shang et al. (2004) unified a framework for multi-criteria evaluation of transportation projects. Piantanakulchai (2005) used Analytic Network Process (ANP) model for highway corridor planning. Naghdi and Babapour (2009) and Hayati et al. (2013) used GIS and AHP for forest road planning. The summary of previous studies on multi-criterion methodologies practiced on highway planning can be found in Table 1 . The summary of previous studies on multi-criterion methodologies practiced on highway planning can be found in Table 1.

Table1. Some of multi-criterion decision making techniques on highway planning

\begin{tabular}{|l|l|}
\hline \multicolumn{1}{|c|}{ Methods } & \multicolumn{1}{c|}{ References } \\
\hline Multi-criteria analysis & Kalamaras et al. (2000) \\
\hline Outranking system & Rogers and Bruen (2000) \\
\hline $\begin{array}{l}\text { Surrogate worth tradeoff, multi-attribute } \\
\text { utility, and minimum tolerance method }\end{array}$ & Tan et al. (2002) \\
\hline AHP & $\begin{array}{l}\text { Azis (1990), Bailey (2006), Naghdi and Babapour } \\
\text { (2009), Hayati et al. (2013) }\end{array}$ \\
\hline ANP & $\begin{array}{l}\text { Piantanakulchai (2005), Shang et al. (2004), Abastante } \\
\text { et al. (2011) }\end{array}$ \\
\hline
\end{tabular}

In this paper, ANP is applied to Pareto solutions from the multi-objective 3D alignment design. Providing the weight of different objectives, priorities of alternatives can be obtained.

\section{The Analytic Network Process (ANP)}

ANP is the generalization of the Analytic Hierarchy Process (AHP). Both AHP and ANP are essentially ways to measure especially intangible factors by using pairwise comparisons with judgments that represent the dominance of one element over another with respect to a property that they share (Chung et al., 2005). However there are more advantages of ANP over AHP since it allows both interaction and feedback within clusters of elements and between clusters. It is preferable to use ANP when the problem involves the interaction and feedback. Many decisions problems cannot be structured hierarchically because they involve the interaction and dependence of higher level elements in a hierarchy on lower level elements (Saaty and Özdemir, 2005).

Refer to Saaty (2005), the methodological point of view of ANP is based on five fundamental steps: (1) structuring of the decision- making problems, (2) clusters and nodes weighting by means of pairwise comparisons, (3) supermatrices formation, (4) elicitation of the final priorities and (5) sensitivity analysis. The supermatix is created based on the combination of cluster and sub-cluster matrices. The global weight obtains by raising the supermatrix with the sufficient large power until the convergence occurs.

The weighted supermatrix $W$ is raised to limit power such as Eq. (1) to get the global priority vectors.

$$
\lim _{k \rightarrow \infty} W^{k}
$$

If the supermatrix has the effect of cyclicity, there may be two or more $\mathrm{N}$ limiting supermatrices. In this case, the Cesaro sum is calculated as in Eq. (2) to get the average priority weights.

$$
\lim _{k \rightarrow \infty}\left(\frac{1}{N}\right) \sum_{i=1}^{N} W_{i}^{k}
$$




\section{Highway Costs}

In order to evaluate the priority of each alignment, it is needed to know the cost associated with each alignment. According to Winfrey (1969), Wright and Dixon (2003), the highway cost can be classified in to several categories: (1) planning, design and administrative costs; (2) construction costs; (3) operations and maintenance costs; (4) user costs and (5) social and environmental costs. Base on this classification, many researchers have tried different optimization techniques to apply in this problem in order to get the optimal or nearly optimal design. However, those optimizations mostly are single objective base which not suitable as a real design in multi-disciplinary.

The most popular optimization technique applied is Genetic Algorithms (GAs). The university of Maryland's research group has conducted the most comprehensive studies in the area of highway design automation. The group's ongoing studies, initiated by Jong (1998), have been advancing over the past decades. Recent researchers extended the technique to apply for multi-objective optimization which can handle the trade-off among different objectives such as Jha and Maji, (2007), Maji and Jha, (2009), Maji and Jha, (2011).

To simplify in the multi-objective optimization purpose, only the conflict objectives are preserved. Those are construction costs, user costs, social impacts and environmental impacts. Detail in cost structures in this model are shown in figure 1.

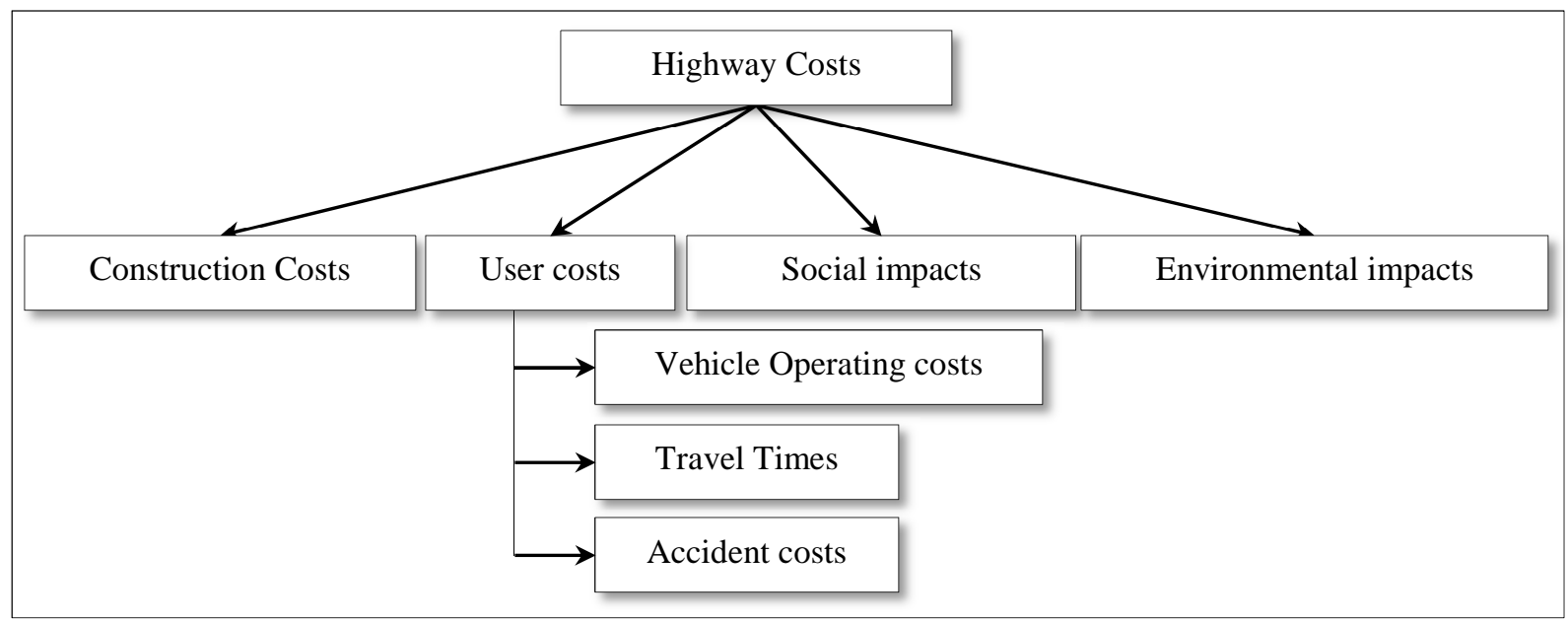

Figure 1. Highway costs consider for this model

\section{Multi-Objective Optimization}

In multi-objective optimization problem, the solution is kept if they are not dominating each other. Non dominated solution set is built under the concept of Pareto Front Optimality (PFO). It is actually the concept in economic with application in engineering. The solutions which are called nondominated solutions set are selected based on its non-dominate feature. Refers to Coello et al. (2004), a point $\vec{x}^{*} \in \Omega$ is Pareto optimal if for every $\vec{x} \in \Omega$ and $I=\{1,2, \ldots, k\}$ either,

$$
\forall_{i \in I}\left(f_{i}(\vec{x})=f_{i}\left(\vec{x}^{*}\right)\right)
$$

or, there is at least one $i \in I$ such that

$$
f_{i}(\vec{x})>f_{i}\left(\vec{x}^{*}\right)
$$

However, it is nearly impossible to evaluate all alternatives among the group of nondominated set, while the solutions may be hundreds. Therefore, the clustering technique is applied to select representative alignments from a solution set. Hierarchical clustering technique used to group objective base on the distance or similarity. The idea behind hierarchical (agglomerative) clustering is to start with each cluster comprising exactly one record and then progressively agglomerating 
(combining) the two nearest clusters until there is just one cluster left at the end, which consists of all the records (Shmueli et al., 2011). In order to cluster the non-dominated solution, first we need to find all pair distances (Euclidean distance) and store in the proximity matrix. Then we make a cluster of the smallest distance of two pairs. The alignments which stand the nearest to the center is denoted as the cluster representative. This process repeat until the target number of clusters is received.

\section{ANP Model structure}

As the above highway costs discussion (section 3), only highway costs which are sensitive to the alignment are considered. The objectives are grouped into 4 clusters (namely construction, user, socio-economic, and environmental aspects) and the relationship between each element is defined. Finally, all the elements in the clusters have been connected to the goal of the evaluation as shown in figure 2 .

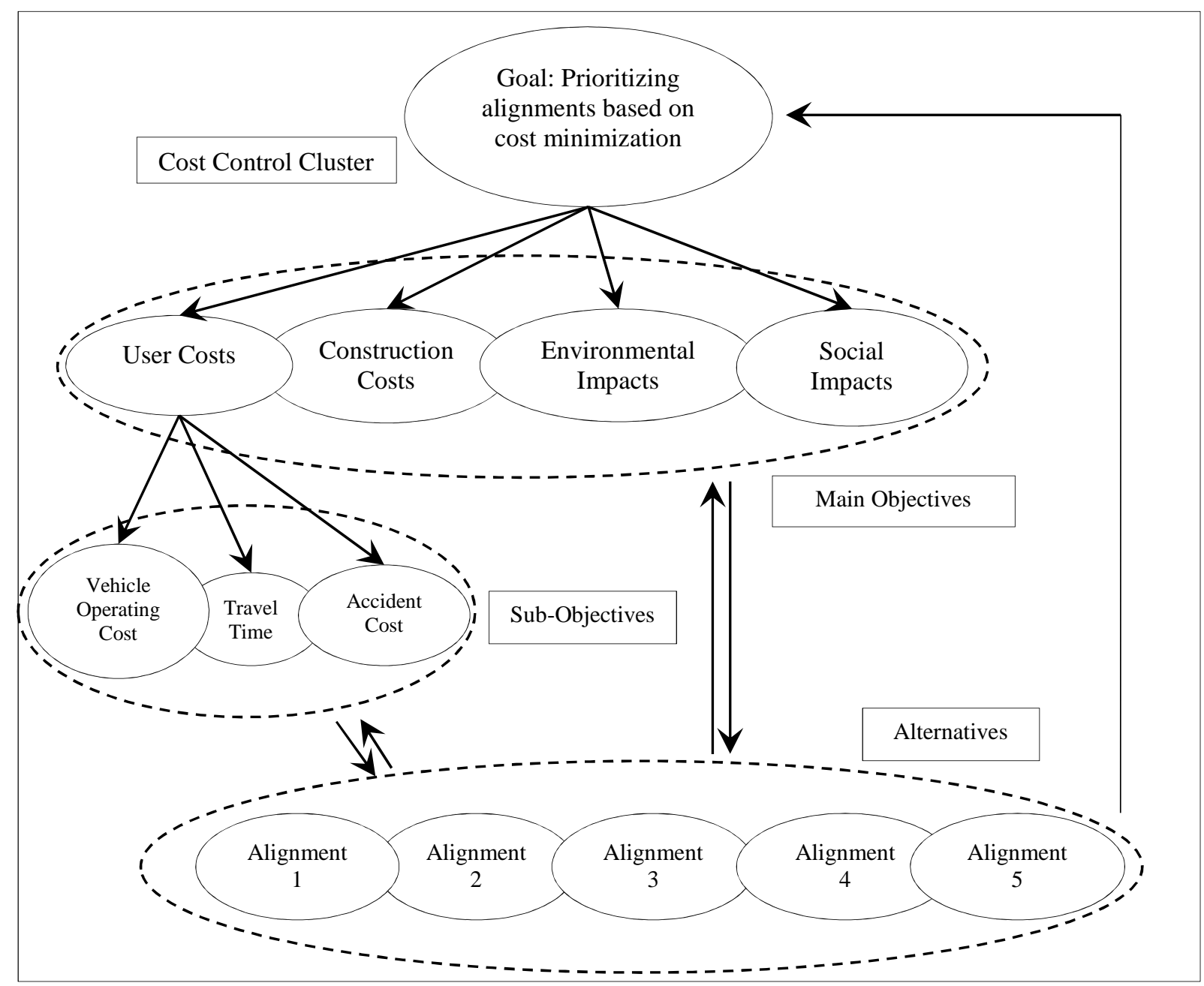

Figure 2. Decision network of the problem

\section{Application of the Model}

\subsection{Case Study}

In order to illustrate the application of the model, the numerical case study is conducted. The result of non-dominated set from multi-objective particle swarm optimization was selected. In this study only 5 alignments are chosen using hierarchical clustering technique as described in section 4. Figure 3 shows the alignment in the map and Table 2 displays the cost associated with each alignment. In 
Table 2, the alignment no. 3 has noticeable properties. It tends to direct the starting and ending points (see Figure 3) which provides shortest length, and having small values of all objectives except the impact on social-economic land use layers. Alignment 3 has a smallest objective values in socioeconomic impact but highest in environmental impact because of trade-off properties. The alignment passes through area of low socio-economic impacts; however it creates a longer distance which leads into high costs in construction.

Table 2. Cost associated to the alternatives

\begin{tabular}{|c|c|c|c|c|c|c|}
\hline \multirow{2}{*}{ Alignment No. } & \multirow{2}{*}{$\begin{array}{c}\text { Construction } \\
\text { Costs (USD) }\end{array}$} & \multicolumn{3}{|c|}{ User Costs (USD) } & $\begin{array}{c}\text { Socio-economic } \\
\text { Impacts } \\
\left(x^{2} 30 \mathrm{~m}^{2}\right)\end{array}$ & $\begin{array}{c}\text { Environmental } \\
\text { Impacts } \\
\left({\mathrm{x} 30 \mathrm{~m}^{2}}^{2}\right.\end{array}$ \\
\hline 1 & $1,787,051$ & $1,324,400$ & $2,151,200$ & 150,370 & 111 & 620 \\
\hline 2 & $1,668,207$ & $1,277,100$ & $2,220,800$ & 156,590 & 106 & 623 \\
\hline 3 & $1,296,930$ & $1,312,400$ & $2,054,700$ & 146,830 & 202 & 508 \\
\hline 4 & $1,411,987$ & $1,342,800$ & $2,260,100$ & 154,080 & 91 & 662 \\
\hline 5 & $1,538,944$ & $1,395,200$ & $2,565,800$ & 164,470 & 61 & 758 \\
\hline
\end{tabular}

There are three different groups of local priority vectors as shown in table 3; (1) the comparison of the objectives respect to each alternative; and (2) the comparison of alternative with respect to each objective (These two local priority vectors can be calculated by normalize ratios). (3) The priority of each objective. It requires the values provided by pair-wise comparison. The preference weight of pair-wise comparison from expert is used to build eigenvector and turn into local priority weight. However, according to the reviews, the local weighted priority of cost aspects and socio-economic aspects and environment aspects are 0.28, 0.649, and 0.071 respectively (Abastante et al., 2011). Another study on alternative selection (Kalamaras et al., 2000) proposed the weight of construction cost, user cost, environmental and positive social impact as 30\%, 20\%, 10\%, 40\% respectively. The element of decision proposed by Kalamaras et al. (2000) is similar to this study except the maximize economic investment. Thus, these weights are adopted directly into the model. However, positive social impacts are not considered. So, the first three objectives were normalized to $50 \%, 33 \%$ and $17 \%$. For the impact of socio-economic land use, we assume the percentage is equally shared.

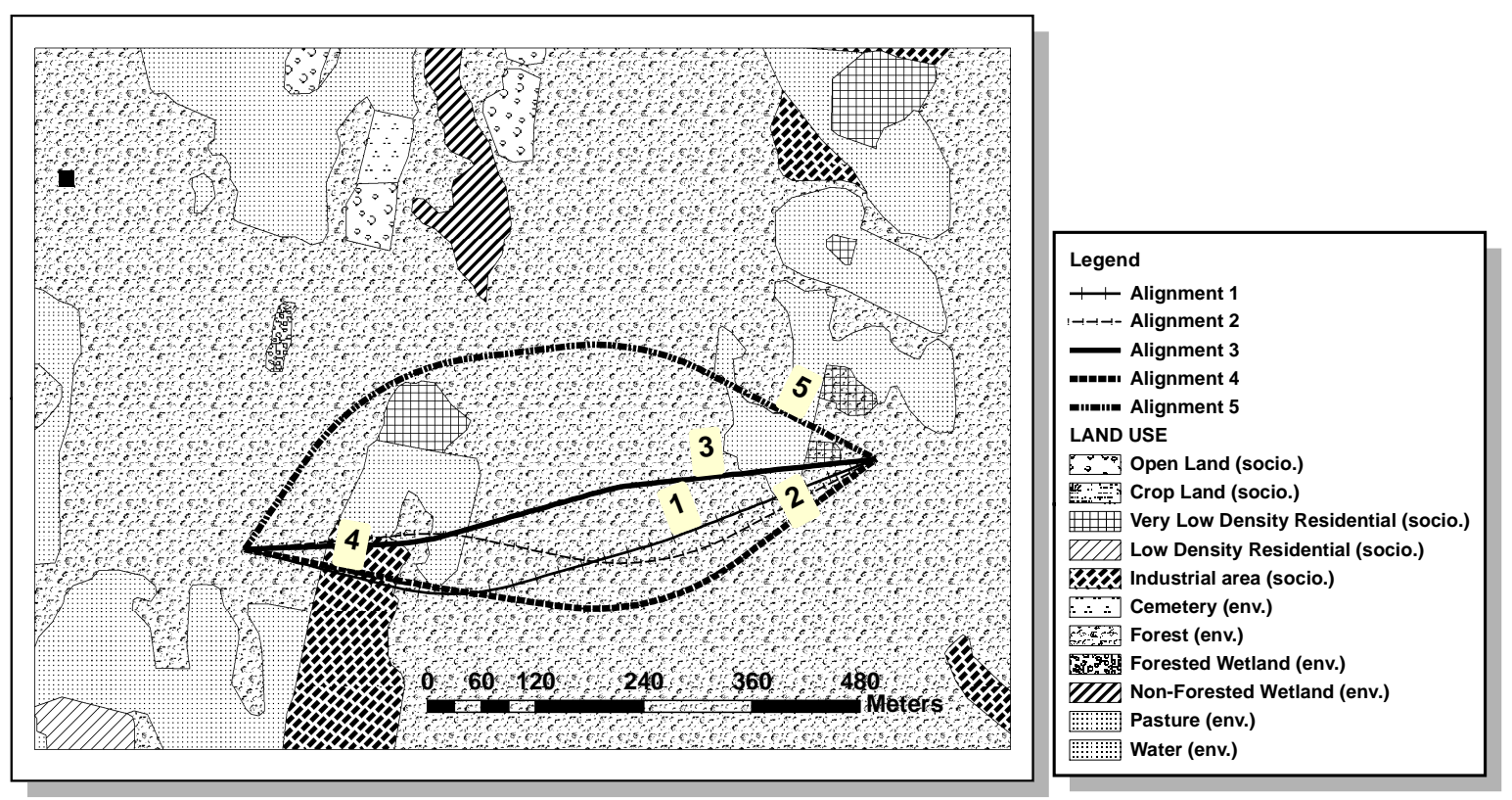

Figure 3. Non Dominated Solutions Generated from Automated Alignment Design

Similarly, refers to Jha et al., (2006) the user costs basically consist of 70-80\% of the totals alignment cost. Furthermore, we assume the weights of various user aspect components are 0.88 (travel time), 0.1 (vehicle operating), 0.02 (accident) out of total weight of user costs. It is similar to 
the percentage share of costs component for user cost using genetic algorithm optimization model in Jha et al. (2006). We also assume 50\% of feedback from alternative cluster to objective cluster. Finally, the supermatrix can be filled as in figure 4:

\begin{tabular}{|c|c|c|c|c|c|c|c|c|c|c|c|c|c|}
\hline & \multirow{2}{*}{ Goal } & \multirow{2}{*}{$\begin{array}{l}\text { Con. } \\
\text { cost }\end{array}$} & \multicolumn{3}{|c|}{ User costs } & \multirow{2}{*}{$\begin{array}{l}\text { Social } \\
\text { Impacts }\end{array}$} & \multirow{2}{*}{$\begin{array}{l}\text { Env. } \\
\text { Impacts }\end{array}$} & \multirow{2}{*}{ Alt. 1} & \multirow{2}{*}{ Alt. 2} & \multirow{2}{*}{ Alt. 3} & \multirow{2}{*}{ Alt. 4} & \multirow{2}{*}{ Alt. 5} \\
\hline & & & & VOC & TTC & $\mathrm{AC}$ & & & & & & & \\
\hline \multicolumn{2}{|c|}{ Goal } & 0.000 & 0.000 & 0.000 & 0.000 & 0.000 & 0.000 & 0.000 & 0.500 & 0.500 & 0.500 & 0.500 & 0.500 \\
\hline \multicolumn{2}{|c|}{ Con. cost } & I 0.500 & I 0.000 & 0.000 & 0.000 & 0.000 & 0.000 & 0.000 & 0.100 & 0.090 & 0.070 & 0.080 & 0.080 \\
\hline \multirow{3}{*}{$\begin{array}{l}0 \\
\tilde{u} \\
0 \\
0 \\
\dot{0} \\
0 \\
0\end{array}$} & VOC & 0.023 & 0.000 & 0.000 & 0.000 & 0.000 & 0.000 & 0.000 & 0.080 & 0.080 & 0.080 & 0.090 & 0.090 \\
\hline & TTC & 0.300 & 0.000 & 0.000 & 0.000 & 0.000 & 0.000 & 0.000 & 0.080 & 0.080 & 0.070 & 0.090 & 0.100 \\
\hline & $\mathrm{AC}$ & 0.007 & 0.000 & 0.000 & 0.000 & 0.000 & 0.000 & 0.000 & 0.080 & 0.090 & 0.080 & 0.090 & 0.090 \\
\hline \multicolumn{2}{|c|}{ Soc. Impacts } & I 0.085 & I 0.000 & 0.000 & 0.000 & 0.000 & 0.000 & 0.000 & 0.080 & 0.080 & 0.130 & 0.060 & 0.040 \\
\hline \multicolumn{2}{|c|}{ Env. Impacts } & 0.085 & 0.000 & 0.000 & 0.000 & 0.000 & 0.000 & 0.000 & 0.080 & 0.080 & 0.070 & 0.090 & 0.100 \\
\hline \multicolumn{2}{|c|}{ Alt. 1} & 0.000 & 0.232 & 0.199 & 0.191 & 0.195 & 0.194 & 0.196 & 0.000 & 0.000 & 0.000 & 0.000 & 0.000 \\
\hline \multicolumn{2}{|c|}{ Alt. 2} & 0.000 & 0.217 & 0.192 & 0.197 & 0.203 & 0.187 & 0.197 & 0.000 & 0.000 & 0.000 & 0.000 & 0.000 \\
\hline \multicolumn{2}{|c|}{ Alt. 3} & 0.000 & 0.168 & 0.197 & 0.183 & 0.190 & 0.354 & 0.160 & 0.000 & 0.000 & 0.000 & 0.000 & 0.000 \\
\hline \multicolumn{2}{|c|}{ Alt. 4} & 0.000 & 0.183 & 0.202 & 0.201 & 0.200 & 0.159 & 0.209 & 0.000 & 0.000 & 0.000 & 0.000 & 0.000 \\
\hline \multicolumn{2}{|c|}{ Alt. 5} & 0.000 & 0.200 & 0.210 & 0.228 & 0.213 & 0.107 & 0.239 & 0.000 & 0.000 & 0.000 & 0.000 & 0.000 \\
\hline
\end{tabular}

i- Required export to provide weights

Comparing alternatives with respect to each objective

Comparing objectives with respect to each alternative

Figure 4. Weighted supermatrix of the model

The result of global priority weights are received by raising a limiting power until it converges. Figure 5 shows the global weight of each element.

\begin{tabular}{|c|c|c|c|c|c|c|c|c|c|c|c|c|c|}
\hline & \multirow{2}{*}{ Goal } & \multirow{2}{*}{$\begin{array}{l}\text { Con. } \\
\text { cost }\end{array}$} & \multicolumn{3}{|c|}{ User costs } & \multirow{2}{*}{$\begin{array}{l}\text { Social } \\
\text { Impacts }\end{array}$} & \multirow{2}{*}{$\begin{array}{l}\text { Env. } \\
\text { Impacts }\end{array}$} & \multirow{2}{*}{ Alt. 1} & \multirow{2}{*}{ Alt. 2} & \multirow{2}{*}{ Alt. 3} & \multirow{2}{*}{ Alt. 4} & \multirow{2}{*}{ Alt. 5} \\
\hline & & & & VOC & TTC & $\mathrm{AC}$ & & & & & & & \\
\hline \multicolumn{2}{|c|}{ Goal } & 200 & 0.200 & 0.200 & 0.200 & 200 & 0.200 & 0.200 & 200 & 0.200 & 0.200 & 0.200 & 0.200 \\
\hline \multicolumn{2}{|c|}{ Con. cost } & 134 & 0.134 & 0.134 & 0.134 & 0.134 & 134 & 134 & 0.134 & 0.134 & 0.134 & 0.134 & 0.134 \\
\hline \multirow{3}{*}{ 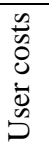 } & VOC & .038 & 0.038 & 0.038 & 0.038 & 0.038 & 0.038 & 0.038 & 0.038 & 0.038 & 0.038 & 0.038 & 0.038 \\
\hline & TTC & 0.094 & 0.094 & 0.094 & 0.094 & 0.094 & 0.094 & 0.094 & 0.094 & 0.094 & 0.094 & 0.094 & 0.094 \\
\hline & $\mathrm{AC}$ & 0.036 & 0.036 & 0.036 & 0.036 & 0.036 & 0.036 & 0.036 & 0.036 & 0.036 & 0.036 & 0.036 & 0.036 \\
\hline \multicolumn{2}{|c|}{$\begin{array}{c}\text { Soc. } \\
\text { Impacts }\end{array}$} & 0.048 & 0.048 & 0.048 & 0.048 & 0.048 & 0.048 & 0.048 & 0.048 & 0.048 & 0.048 & 0.048 & 0.048 \\
\hline \multicolumn{2}{|c|}{$\begin{array}{l}\text { Env. } \\
\text { Impacts }\end{array}$} & 0.051 & 0.051 & 0.051 & 0.051 & 0.051 & 0.051 & 0.051 & 0.051 & 0.051 & 0.051 & 0.051 & 0.051 \\
\hline \multicolumn{2}{|c|}{ Alt. 1} & & & 0.083 & & & & & & & & & 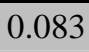 \\
\hline \multicolumn{2}{|c|}{ Alt. 2} & & & 0.081 & 0.081 & 0.0 & & & & & & & 0.081 \\
\hline \multicolumn{2}{|c|}{ Alt. 3} & 0.079 & 0.079 & 0.079 & 0.079 & 0.079 & & & & & .079 & 0.079 & 0.079 \\
\hline \multicolumn{2}{|c|}{ Alt. 4} & 0.076 & 0.076 & 0.076 & 0.076 & 0.076 & & 076 & 0.076 & 0.076 & 0.076 & 0.076 & 0.076 \\
\hline \multicolumn{2}{|c|}{ Alt. 5} & 0.081 & 0.081 & 0.081 & 0.081 & 0.081 & 0.081 & 0.081 & 0.081 & 0.081 & 0.081 & 0.081 & 0.081 \\
\hline
\end{tabular}

Figure 5. Limiting supermatrix

Table 3. Ranked Alternatives Based on Costs

\begin{tabular}{|ccc|}
\hline Alignments & Priorities & Rank \\
\hline 1 & 0.083 & 5 \\
2 & 0.081 & 4 \\
3 & 0.079 & 2 \\
4 & 0.076 & 1 \\
5 & 0.081 & 3 \\
\hline
\end{tabular}

*Small priority means lower costs 


\subsection{Sensitivity Analysis}

Considering different level of feedback from alternatives to objectives, the different weights of alternatives can be found. Figure 6 presents the weight from different feedback level. In case of 100\% feedback level, it means that the objectives are weighted based on the dominate feature of alternatives (efficiency) only. On the other hand, if the level of feedback is set to 0\% the ANP reduce to AHP and the objective are weighted by predefined weights from experts (literatures).

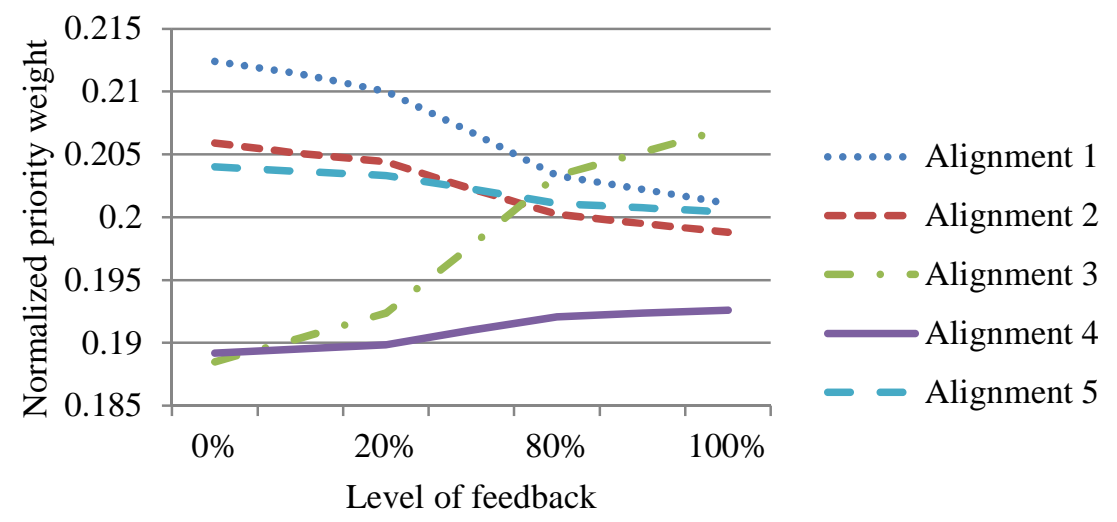

Figure 6. Sensitivity analysis by levels of feedback to the objectives

\section{Discussion of Results}

The result of the model coming from the global priority weights provides some interesting findings which can be described as follows. Figure 5 shows the non-normalized weight of alternative and weights of each decision element. In table 3, alternatives are ranked according to the costs which means the less the weight is, the lower the cost is (more preferable). The weight of alignment 4 is lower compared to others. From the result of sensitivity analysis, considering only the dominant feature among alternative, alignment 4 is more preferable. In addition, alignment 3 ranks $1^{\text {st }}$ with $100 \%$ feedback and turns into $5^{\text {th }}$ when there is no feedbacks. In general, the alignment 4 shows its robustness both on alignment efficiency itself and also the priority weight provided by experts (Figure 6). The result shows the trade-off between the efficiency of alignment itself with weight provided by expert. Moreover the weight of each alternative is quite similar (around 0.2). This is because of alternatives are already the good solutions which are selected based on the concept of Pareto front Optimality (PFO).

\section{Conclusion}

This paper presented ANP as a supporting tool of multi-objective optimization in automated highway design. The importance of each alternative based on reviews and the feedback from alternative itself are taken into account. ANP helps to prioritize road alternatives, with respecting to the minimization objective from optimization model. Future work should be focused on using the ratios of preferences instead of using the ratios of objective values.

\section{REFERENCES}

Abastante, F., Lami, I.M., Bottero, M.C., 2011. Using the analytic network process (anp) for ranking the critical issues of a transport decision problem: the italian section of the corridor 24 [ $W W W$ Document]. URL http://porto.polito.it/2426778/(accessed 2.17.13).

Azis, I.J., 1990. Analytic Hierarchy Process in the benefit-cost framework: A post-evaluation of the Trans-Sumatra highway project. European Journal of Operational Research 48, 38-48. 
Bailey, K., 2006. Principles of the EP-AMIS GIS/Multicriteria methodology for Participatory Electric Power Transmission Line Routing, in: Power Systems Conference and Exposition, 2006. PSCE '06. 2006 IEEE PES. Presented at the Power Systems Conference and Exposition, 2006. PSCE '06. 2006 IEEE PES, pp. $385-388$.

Chung, S.-H., Lee, A.H.I., Pearn, W.L., 2005. Analytic network process (ANP) approach for product mix planning in semiconductor fabricator. International Journal of Production Economics 96, $15-36$.

Coello, C.A.C., Pulido, G.T., Lechuga, M.S., 2004. Handling multiple objectives with particle swarm optimization. IEEE Transactions on Evolutionary Computation 8, 256 - 279.

FHWA, U.S.F.H.A.O. of A., 2003. Economic analysis primer. Office of Asset Management, U.S. Federal Highway Administration.

Hayati, E., Majnounian, B., Abdi, E., Sessions, J., Makhdoum, M., 2013. An expert-based approach to forest road network planning by combining Delphi and spatial multi-criteria evaluation. Environ Monit Assess 185, 1767-1776.

Jha, M.K., Maji, A., 2007. A Multi-Objective Genetic Algorithm for Optimizing Highway Alignments, in: IEEE Symposium on Computational Intelligence in Multicriteria Decision Making. Presented at the IEEE Symposium on Computational Intelligence in Multicriteria Decision Making, IEEE, pp. 261-266.

Jha, M.K., Schonfeld, P., Jong, J.-C., KIM, E., 2006. Intelligent Road Design, Advances in Transport, Vol. 19. WIT Press, Ashurst Lodge, Ashurst, Southampton, SO40 7AA, UK.

Kalamaras, G.S., Brino, L., Carrieri, G., Pline, C., Grasso, P., 2000. Application of Multicriteria Analysis to select the best highway alignment. Tunnelling and Underground Space Technology 15, 415-420.

Maji, A., Jha, M.K., 2009. Multi-objective highway alignment optimization using a genetic algorithm. Journal of Advanced Transportation 43, 481-504.

Maji, A., Jha, M.K., 2011. A Multiobjective Analysis of Impacted Area of Environmentally Preserved Land and Alignment Cost for Sustainable Highway Infrastructure Design. Procedia - Social and Behavioral Sciences 20, 966-972.

Naghdi, R., Babapour, R., 2009. Planning and Evaluating of Forest Roads Network with Respect to Environmental Aspects via GIS Application (Case Study: Shafaroud Forest, Northern Iran ), in: Second International Conference on Environmental and Computer Science, 2009. ICECS '09. Presented at the Second International Conference on Environmental and Computer Science, 2009. ICECS '09, pp. $424-427$.

Piantanakulchai, M., 2005. Analytic Network Process Model For Highway Corridor Planning. ISAHP 2005, Honolulu, Hawaii, July 8-10, 2005

Rogers, M., Bruen, M., 2000. Using Electre Iii To Choose Route For Dublin Port Motorway. Journal of Transportation Engineering 126.

Saaty, T.L., Özdemir, M.S., 2005. The Encyclicon: A Dictionary of Decisions with Dependence and Feedback Based on the Analytic Network Process. Research Publication.

Saaty, T.L. (2005). Theory and Applications of the Analytic Network Process: Decision Making with Benefits, Opportunities, Costs, and Risks. Pittsburgh: RWS Publications.

Shang, J.S., Tjader, Y., Ding, Y., 2004. A unified framework for multicriteria evaluation of transportation projects. IEEE Transactions on Engineering Management 51, $300-313$.

Shmueli, G., Patel, N.R., Bruce, P.C., 2011. Data Mining for Business Intelligence: Concepts, Techniques, and Applications in Microsoft Office Excel with XLMiner. John Wiley \& Sons.

Tan, P., William, S., Chowdhury, M., 2002. An interactive multiobjective decision support framework for transportation investment [WWW Document]. URL http://digital.library.wisc.edu/1793/6913

Winfrey, R., 1969. Economic analysis for highways, First Edition. ed. International Textbook Co. Wright, P.H., Dixon, K., 2003. Highway Engineering, 7th ed. Wiley. 